\title{
HARDWARE CONTROL PADA ROBOT PEMINDAH BUNGA
}

\author{
Yunifa Miftachul Arif \\ Jurusan Teknik Informatika, Fakultas Saintek, UIN Maulana Malik Ibrahim Malang
}

\begin{abstract}
Abstrak - Teknologi robot yang berkembang pesat saat ini diharapkan dapat bermanfaat untuk segala bidang salah satunya adalah bidang rumah tangga. Pada penelitian ini dirancang dan dibuat sebuah robot yang dapat meletakkan bunga pada jambangan vas tanaman. Robot ini adalah robot vision yang dapat bergerak secara otomatis di dalam suatu ruangan yang terbatas. Kamera yang digunakan sebagai sensor untuk mengidentifikasi objek yang berupa bunga dan vas bunga adalah kamera webcam. Bunga yang sudah terdeteksi kamera akan diolah komputer menjadi data posisi dan data luasan. Data tersebut dikirimkan ke mikrokontroller ATmegal6 melalui komunikasi serial RS232. Penelitian lebih dititik beratkan pada sistem pengontrolan hardware dan mekanik robot, mulai data diterima melalui komunikasi serial RS232 sampai dengan menjadi pergerakan robot. Pada penelitian ini input data posisi digunakan oleh mikrokotroller sebagai referensi posisi robot terhadap objek untuk menggerakkan motor roda kanan dan motor roda kiri sedemikian rupa sehingga robot dapat bergerak menuju objek dan berada tepat didepan objek. Sedangkan data luasan digunakan sebagai data referensi mikrokontroler untuk mengetahui seberapa dekat jarak robot terhadap objek. Setelah mendapat nilai luasan yang cukup maka robot dapat melakukan proses selanjutnya, yaitu mengambil bunga dan meletakkan bunga tersebut pada vas bunga. Sistem mekanik robot dilengkapi lengan buatan dengan penjepit pada ujungnya dimana semua gerakan lengan dan penjepit digerakkan menggunakan motor DC. Dari hasil percobaan yang dilakukan dapat disimpulkan bahwa sistem hardware cantrol sudah cukup mendukung sistem vision robot yang diproses oleh komputer. Dimana dalam 10 kali percobaan, rata-rata 73,33\% robot berhasil menyeleseikan tugasnya untuk mengambil dan meletakkan bunga pada vas.
\end{abstract}

Kata kunci: Robot, bunga, mikrokontroler, komunikasi serial, motor DC

\section{PENDAHULUAN}

Robot pada awal mulanya berasal dari kata dalam bahasa Czech, yakni robota, yang mempunyai arti pekerja. mulai menjadi popular ketika seorang penulis berbangsa Czech (Ceko), Karl Capek, membuat pertunjukan dari lakon komedi yang ditulisnya pada tahun 1921 yang berjudul RUR (Rossum's Universal Robot). Definisi awal dari robot dikatakan sebagai segala peralatan otomatis yang dibuat untuk menggantikan fungsi yang selama ini dilakukan oleh manusia. Namun dalam perkembangan selanjutnya, robot diartikan sebagai manipulator multi ungsional yang dapat diprogram, yang dengan pemrograman itu ditujukan untuk melakukan sesuatu tugas tertentu (Pitowarno, 2006:1).
Industri pembuatan robot telah menjadi sebuah revolusi di bidang industri. Robot - robot yang diciptakan tidak memiliki tingkah laku dan kemampuan seperti manusia, namun hanya dapat membantu atau menggantikan satu dari sekian banyak pekerjaan manusia. Salah satunya robot yang mempunyai kemampuan seperti manusia yaitu robot yang dapat meletakkan bunga pada vas tanaman. Robot ini dapat mendeteksi dan meletakkan bunga pada vas bunga. Wadah atau vas bunga digunakan untuk menempatkan rangkaian bunga. Beberapa bentuk dasar desain rangkaian bunga diantaranya lingkaran, segitiga, dan segi empat (Murtiningsih, 2006:58).

Untuk memenuhi kebutuhan pengindraan dalam bentuk citra pada 
Robot Pemindah bunga, maka dikembangkan suatu sistem visual pada robot yang dapat melakukan proses mengenali objek dan membedakan warna objek. Setiap informasi mengenai objek dari kamera, diolah pada komputer selanjutnya komputer memberikan instruksi dan informasi kepada mikrokontroler robot melalui komunikasi serial RS232. Dari informasi yang diperoleh tersebut, setiap gerakan robot terhadap objek dikontrol dengan menggunakan mikrokontroler. Mikrokontroler juga mendapatkan input dari limit switch dan sensor photodiode yang merupakan sensor pembatas gerak lengan pada saat robot melakukan gerakan merangkai bunga.

\section{PERMASALAHAN}

Pada penelitian ini, masalah yang akan diteliti adalah perancangan sistem kontrol hardware dan mekanik pada Robot Pemindah Bunga agar mampu melakukan gerakan-gerakan antara lain menjepit tangkai bunga serta meletakkannya pada vas sesuai dengan instruksi dari komputer.

Dari penjelasan diatas, maka dapat diketahui permasalahan pada penelitian ini meliputi:

1. Bagaimana membuat perangkat keras elektronik pada minimum sistem berbasis mikrokontroller, komunikasi serial RS232, dan driver motor DC dua arah putar.

2. Bagaimana algoritma sistem untuk menunjang kinerja robot antara lain : maju, mundur, belok kanan, belok kiri, mengambil bunga dan meletakkan bunga.

3. Bagaimana membuat sebuah mekanik yang tepat sehingga robot dapat berjalan sesuai dengan fungsi yang diharapkan.

\section{Batasan Masalah}

Asumsi-asumsi berikut ini adalah sebagai batasan masalah yang menjadi acuan dalam penelitian ini:
1. Mobilitas robot hanya pada lantai yang rata atau memiliki ketinggian yang sama.

2. Besar tangkai bunga adalah antara 2 hingga $6 \mathrm{~mm}$.

3. Robot hanya mengenal 2 obyek yaitu bunga dan vas bunga, dan hanya bertugas mengambil 3 buah bunga dengan warna merah, kuning dan biru.

\section{TINJAUAN PUSTAKA}

\section{a. Robot Berorientasi Fungsi}

Robot Pemindah Bunga adalah salah satu bentuk robot berorientasi fungsi yang mempunyai komponen utama, antara lain: Mekanik robot, sensor, aktuator dan sistem kontroler. Gambar 2.1 berikut ini mengilustrasikan tentang sebuah diagram sistem robot yang berorientasi fungsi (Pitowarno, 2006:43).

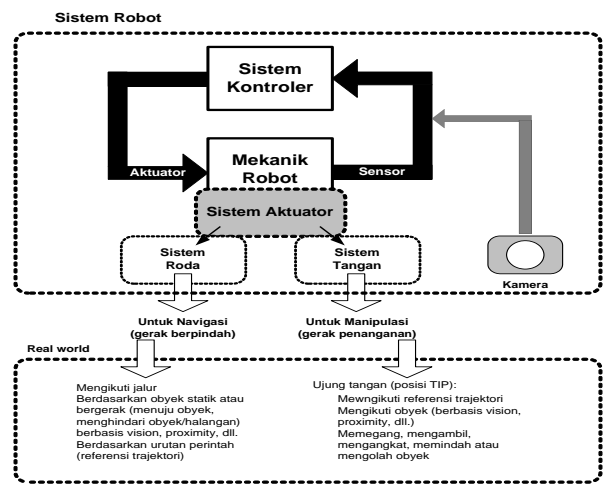

Gambar 2.1 Sistem Robot dan Orientasi Fungsi

\section{b. Mikrokontroller Atmel AVR ATmega16}

AVR merupakan seri mikrokontroler CMOS 8-bit buatan Atmel, berbasis arsitektur RISC (Reduced Instruction Set Computer). Hampir semua instruksi dieksekusi dalam satu siklus clock. AVR mempunyai 32 register general-purpose, timer/counter fleksibel dengan mode compare, interrupt internal dan eksternal, serial UART, programmable Watchdog Timer, dan mode power saving. Mempunyai ADC dan PWM internal. AVR juga mempunyai In-System Programmable Flash on-chip yang mengijinkan memori program untuk diprogram ulang dalam sistem menggunakan hubungan serial SPI. 
Atmega16 adalah mikrokontroler CMOS 8bit daya-rendah berbasis arsitektur RISC yang ditingkatkan.

Kebanyakan instruksi dikerjakan pada satu siklus clock, Atmega16 mempunyai throughput mendekati 1 MIPS per $\mathrm{MHz}$ membuat disainer sistem untuk mengoptimasi komsumsi daya versus kecepatan proses.

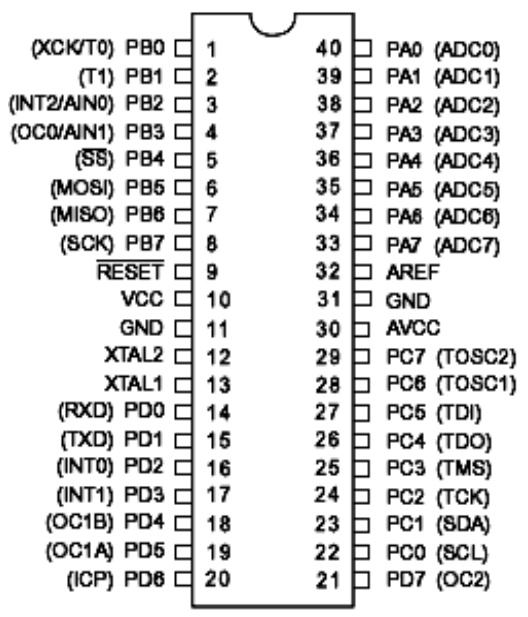

\section{Gambar 2.2 Pin-pin ATmegal6 kemasan 40-pin}

Pin-pin pada ATmega16 dengan kemasan 40-pin DIP (dual in-line package) ditunjukkan oleh gambar 2.2.

Software yang digunakan untuk mengisi program pada mikrokontroller AVR adalah CodeVision AVR dimana bahasa pemrograman yang digunakan adalah bahasa $\mathrm{C}$.

\section{c. Sensor Limit switch}

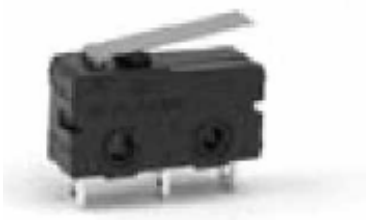

\section{Gambar 2.3 Bentuk Fisik Limit switch}

Switch digunakan untuk hal-hal yang berhubungan dengan jarak, kepekaan, deteksi ada tidaknya barang, maupun kontak pembatas. Sensor limit switch digunakan untuk pengaturan posisi lengan robot. Bentuk fisik limit switch ditunjukkan pada gambar 2.3.

\section{d. Sensor Photodiode}

Photodiode mempunyai daerah deplesi dengan medan listrik yang tinggi yang menyebabkan pemisahan pasangan elektron hole secara photogeneration. Untuk operasi kerja yang tingi, daerah deplesi harus dijaga ketipisannya untuk mereduksi waktu transit. Dengan kata lain peningkatan efisiensi kuantum (jumlah pasangan elektron dihasilkan perphoton yang timbul). Lapisan deplesi harus cukup tebal untuk menyerap sebagian besar cahaya.

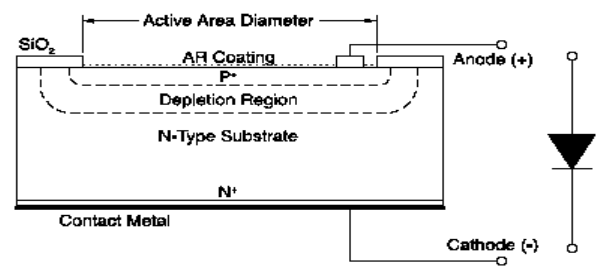

\section{Gambar 2.4 Struktur dari photodiode}

Photodiode dapat dioperasikan photovoltaic, photodiode dalam keadaan tidak terbias dan terhubung pada impedansi beban sama seperti solarsel yang akan diuraikan. Selanjutnya bagaimanapun juga desain piranti ini berbeda secara dasarnya. Pada photodiode hanya range panjang gelombang yang sempit terpusat pada panjang gelombang sinyal optik merupakan hal yang penting. Photodiode sulit untuk memperkecil kapasitansi junction dan satu hal yang terpenting daripada photodiode adalah efisiensi kuantum. P-I-N photodiode adalah salah satu photodetektor yang paling umum oleh karena daerah deplesi yang lebar (lapisan instinstik) yang dapat mengoptimalisasi efisiensi kuantum dan respon frekuensinya. Penyerapan cahaya padasemikonduktor menghasilkan pasangan elektron-hole pasangan elektonhole menghasil-kan daerah deplesi atau panjang difusi dari pasangan elektron hole akan dipisahkan oleh medan listrik 
dimana arus mengalir kedalam rangkaian eksternal sebagai carieer drift melalui lapisan deplesi. Ketebalan lapisan instrinsik dioptimalisasikan untuk panjang gelombang sinyal optik dan frekuensi modulasi.

\section{e. Komunikasi Serial RS232}

RS232 merupakan salah satu standar interface dalam proses transfer data antar computer terutama dalam bentuk serial transfer. RS232 merupakan kependekan dari Recommended Standard number 232. Standar ini dibuat oleh Elektronik Industri Association (EIA), untuk interface antara peralatan terminal data dan peralatan komunikasi data, dengan menggunakan data biner sebagai data yang ditransmisi. RS232 adalah suatu Serial Data Interface Standard yang dikeluarkan oleh EIA. Standarisasi meliputi konektor, fungsi serta posisi tiap per timing(pewaktu) dan level tegangan / arus. Standar ini juga berisikan karakteristik sinyal listrik, karakteristik mekanik dan cara operasional rangkaian fungsional.

Dalam penelitian ini komunikasi data yang digunakan untuk menghubungkan perangkat komputer dengan mikrokontroler adalah komuikasi serial, sedangkan protokolnya menggunakan RS-232. Dalam teknik interfacing untuk menunjang standar RS-232 diperlukan adanya IC yang mendukung komunikasi, dan disini digunakan MAXIM MAX232.

\section{f. Motor DC}

Motor DC pada saat ini digunakan pada industri yang memerlukan gerakan dengan kepresisian yang sangat tinggi untuk pengaturan kecepatan pada torsi yang konstan. Motor DC berfungsi mengubah tenaga listrik menjadi tenaga mekanis dimana gerak tersebut berupa putaran dari motor.

Suatu motor listrik disebut sebagai motor DC jika memerlukan supplay tegangan searah pada kumparan jangkar dan kumparan medan untuk diubah menjadi energi mekanik. Pada motor DC, kumparan medan yang dialiri arus listrik akan menghasilkan medan magnet yang melingkupi kumparan jangkar dengan arah tertentu. Konversi energi listrik yang diubah menjadi energi mekanik berlangsung melalui medium medan magnet. Energi yang akan diubah dari suatu sistem yang lainya, sementara akan disimpan dalam medium medan magnet untuk kemudian dilepaskan menjadi energi sistem lainya.

Kontruksi dasar dari sebuah motor DC ditunjukkan seperti pada gambar 2.6.

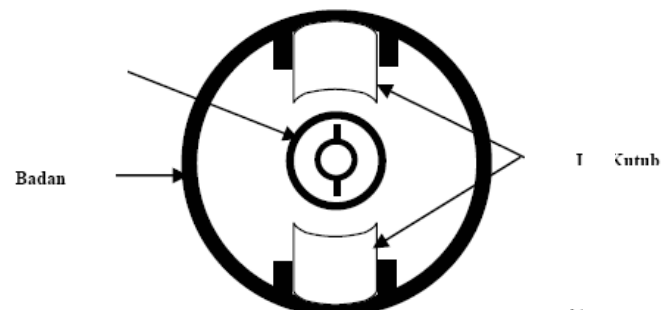

Gambar 2.6 Bagian-Bagian Motor DC

\section{PERENCANAAN DAN PEMBUATAN ROBOT}

\section{a. Konfigurasi Sistem}

Secara umum sistem kontrol yang terdapat pada Robot Pemindah Bunga terdiri atas bagian perangkat keras(hardware) dan perangkat lunak (software). Untuk pembuatan perangkat keras yang meliputi pembuatan perangkat mekanik serta perangkat keras elektonik (hardware) akan dibahas pada bab ini yang merupakan pokok bahasan utama dalam penelitian ini.

Perangkat mekanik yang menggunakan bahan aluminium yaitu tubuh robot, lengan robot, dan penjepit tangkai bunga. Sedangkan pembuatan perangkat keras elektronik terdiri dari rangkaian sistem minimum mikrokontroler ATMEGA16, penggerak (driver) motor DC dan rangkaian komunikasi data serial RS232.

Gambaran sistem secara keseluruhan pada penelitian ini ditunjukkan pada gambar 3.1. 


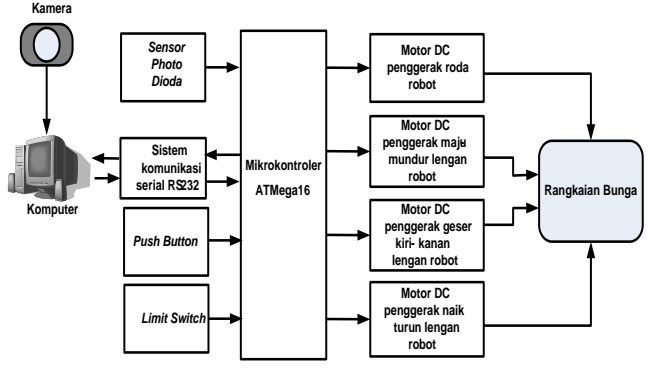

Gambar 3.1 Blok Diagram Sistem

Sedangkan flowchart sistem dari Robot Pemindah bunga pada penelitian ini ditunjukkan pada gambar 3.2.

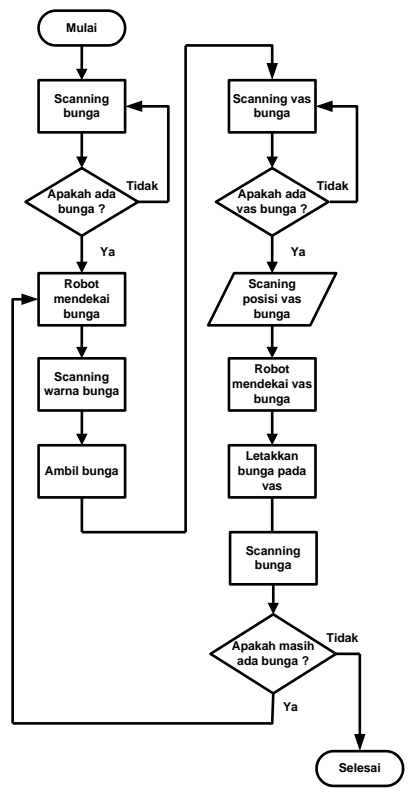

Gambar 3.2 Flow chart sistem

Informasi data yang berupa obyek gambar diterima kamera kemudian data informasi tersebut dikirim dan diolah oleh komputer menjadi suatu data yang diinginkan untuk proses selanjutnya yaitu berupa data letak objek terhadap kamera serta data luasan objek. Data tersebut dikirimkan kepada mikrokontroler ATMEGA16 menggunakan komunikasi serial RS232, dimana selanjutnya diolah menjadi instruksi untuk menjalankan motor pada robot. Robot bergerak secara otomatis sesuai dengan informasi yang diterima dari posisi objek yang diterima oleh kamera. Pergerakan yang dilakukan oleh robot pada penelitian ini meliputi gerak maju-mundur, belok kiri- kanan, mengambil bunga dan meletakkan bunga.

\section{b. Perancangan Mekanik Robot}

Robot dirancang agar dapat melaksanakan tugas dan fungsinya dengan baik dan akurat. Untuk mencapai kondisi diatas maka yang perlu diperhatikan dari pembuatan mekanik adalah mulai dari pemilihan bahan, desain konstruksi, kekuatan motor dan ketepatan pemasangan gearbox baik pada roda utama maupun pada lengan robot.

Pada penelitian ini, kerangka robot terbuat dari alumunium dengan alasan bahan ini cukup kuat untuk menopang motor dan gearbox. Selain itu alumunium juga tergolong bahan yang ringan sehingga tidak akan terlalu membebani robot dan diharapkan robot dapat melakukan respon yang cepat terhadap instruksi dari mikrokontroler.

Dalam menggerakkan kedua roda kanan - kiri dan untuk menggerakkan lengan maju-mundur, naik-turun, geser kiri-kanan, serta gerak menjepit tangkai bunga digunakan motor DC 24 Volt. Untuk menggerakkan roda utama robot digunakan motor yang mempunyai gerabox, dengan tujuan untuk memperoleh torsi yang besar dan untuk memperoleh keseimbangan gerakan antara roda kanan dan kiri.

Gerak naik-turun lengan pada ini memanfaatkan tali sebagai media penarik, dimana tali tersebut digulung dengan menggunakan putaran motor. Sedangkan untuk gerak turun lengan, memanfaatkan berat dari lengan itu sendiri sebagai penarik lengan turun, sehingga motor hanya berputar berlawanan arah untuk mendapatkan gerakan tersebut. Pada gerak geser kirikanan dan maju-mundur menggunakan belt, sedangkan gerakan penjepit media yang digunakan adalah ulir yang diputar oleh masing motor DC. Hal ini bertujuan untuk mendapatkan gerak lengan yang lebih kuat agar bunga tidak mudah lepas dari penjepit ketika robot bergerak menuju vas bunga.

$$
\text { Created with }
$$




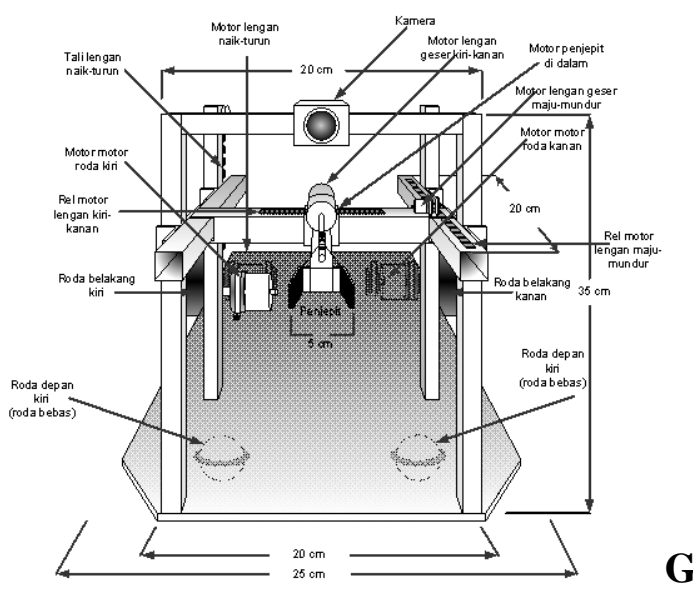

Gambar 3.3 Gambar Rancangan

Mekanik Robot Tampak Depan

Sesuai dengan gambar 3.3, untuk melakukan gerakan mengambil bunga, proses yang harus dilakukan robot adalah lengan maju, tutup penjepit, langan naik, kemudian lengan mundur. Sedangkan untuk melakukan gerakan meletakkan bunga, gerakan yang harus dilakukan robot adalah lengan maju, buka penjepit, dan terhir adalah lengan mundur.

\section{c. Perancangan dan Pembuatan Rangkaian Masukan Robot Rangkaian Sensor Photodiode \\ Rangkaian sensor photodiode} digunakan sebagai sensor pembatas gerakan lengan agar berada lurus dengan sisi tengah robot. Letak sensor pada robot adalah pada bagian bawah lengan robot yang dilengkapi dengan garis putih sebagai objek pembacaan sensor.

Rangkaian sensor terdiri dari LED sebagai piranti yang memancarkan cahaya, dan photodiode sebagai piranti yang akan menerima pantulan cahaya LED pada lengan. Rangkaian komparator akan membandingkan tegangan input dari sensor dengan tegangan referensi sehingga menghasilkan logika ' 0 " dan "1" yang digunakan untuk membedakan antara lengan dan garis.

Berikut ini adalah gambar rangkaian sensor dan rangkaian komparator yang ditunjukkan pada gambar 3.4.

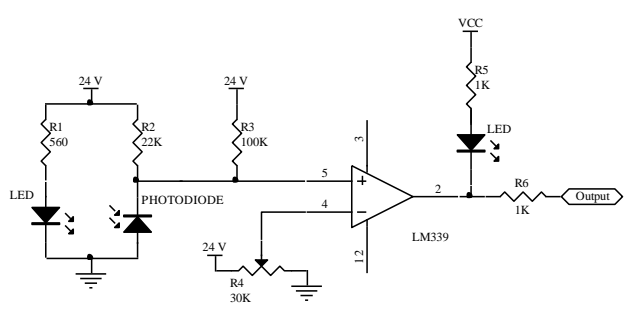

Gambar 3.4 Rangkaian sensor dan komparator

\section{Sistem Komunikasi Serial RS232}

Rangkaian komunikasi serial menggunakan IC MAX232 ditunjukkan pada gambar 3.5. Rangkaian ini berfungsi untuk mengubah level keluaran tegangan yang keluar dari komputer yaitu level RS232 menjadi level tegangan TTL. Dimana tegangan pada level RS232 menjadi level logika "1" didefinisikan - 3 volt sampai -15 dan logika "0" didefinisikan +3 volt sampai +15 volt. Pada level TTL yang didefinisikan untuk kondisi "0" volt sampai 0,4 volt dan untuk kondisi "1", tegangannya 2,4 volt sampai 5 volt.

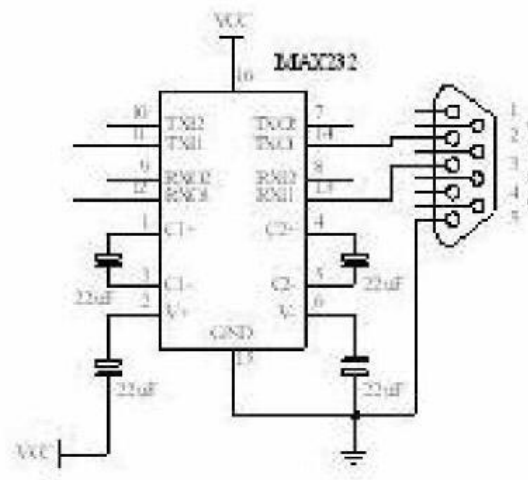

Gambar 3.5 Rangkaian Komunikasi Serial RS232

Sistem ini digunakan sebagai media komunikasi antara PC dengan minimum sistem mikrokontroler. Dalam hal ini PC melalui interface RS232 mengirimkan kombinasi karakter dan angka ke mikrokontroler yang merupakan data letak objek terhadap kamera dan besar luasan objek. Selanjutnya data tersebut diolah oleh mikrokontroler menjadi perintah gerak sistem mekanik robot. Selain menerima, mikrokontroler juga 
mengirimkan data ke PC, yang digunakan sebagai penanda untuk beberapa proses yang sudah terseleseikan.

\section{Bagian Pengendali Robot}

Pada penelitian ini dibuat piranti penggendali menggunakan mikrokontroler keluaran ATMEL yaitu ATMEGA16. Untuk mengaktifkan atau menjalankan mikrokontroler ini diperlukan rangkaian minimum sistem

Rangkaian I/O dari mikrokontroller mempunyai kontrol direksi yang tiap bitnya dapat dikonfigurasikan secara individual, maka dalam pengkonfigurasian I/O yang digunakan ada yang berupa operasi port ada pula yang dikonfigurasi tiap bit I/O. Berikut ini adalah konfigurasi $\mathrm{I} / \mathrm{O}$ masingmasing port mikrokontroller :

\section{- Port A}

- Port A.0 sebagai input sensor limit switch batas-bawah lengan

- Port A.1 sebagai input sensor limit switch batas-atas lengan

- Port A.2 sebagai input sensor limit switch batas-kiri lengan

- Port A.3 sebagai input sensor limit switch batas-kanan lengan

- Port A.4 sebagai input sensor limit switch batas-depan lengan

- Port A.5 sebagai input sensor limit switch batas-belakang lengan

- Port A.6 sebagai output driver motor untuk motor lengan naik-turun

- Port A.7 sebagai output driver relay pembalik polaritas motor untuk motor lengan naik-turun

\section{- Port B}

- Port B.0 sebagai input sensor photodiode

\section{- Port C}

- Port C.2 sebagai output driver motor untuk motor lengan jepit-buka

- Port C.3 sebagai output driver relay pembalik polaritas motor untuk motor lengan jepit-buka

- Port C.4 sebagai output driver motor untuk motor lengan maju-mundur
- Port C.5 sebagai output driver relay pembalik polaritas motor untuk motor lengan maju-mundur

- Port C.6 sebagai output driver motor untuk motor lengan geser kirikanan

- Port C.7 sebagai output driver relay pembalik polaritas motor untuk motor lengan geser kiri-kanan

\section{- Port D}

- Port D.3 sebagai output driver relay pembalik polaritas motor untuk motor penggerak kiri

- Port D.4 sebagai output driver motor untuk motor penggerak kiri

- Port D.5 sebagai output driver relay pembalik polaritas motor untuk motor penggerak kanan

- Port D.6 sebagai output driver motor untuk motor penggerak kanan

- Port D.7 sebagai input push button start

\section{d. Bagian keluaran Robot \\ e. Driver motor}

Pada penelitian ini, robot pemindah bunga mempunyai 2 motor DC yang untuk melakukan gerakan maju, mundur, belok kiri, juga belok kanan. Oleh karenanya dibutuhkan rangkaian driver motor yang mempunyai dua arah putar. Rangkaian driver motor dibuat dengan maksimal tegangan $\mathrm{Vcc} 24 \mathrm{~V}$ dan arus 5A, menyesuaikan spesifikasi motor DC yang digunakan. Rangkaian driver motor dua arah putar yang dimaksud ditunjukkan pada gambar 3.6.

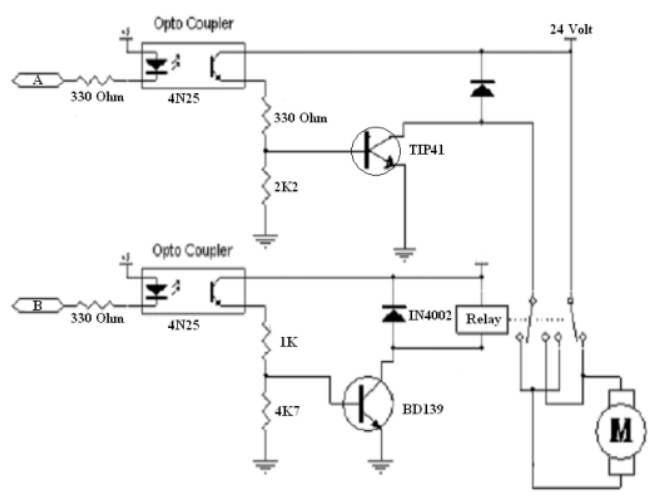

Gambar 3.6 Rangkaian Driver motor DC 
Pada gambar 3.6, relay digunakan sebagai pembalik polaritas motor. Sedangkan transistor TIP41 digunakan sebagai komponen penggerak motor DC. Untuk membalik polaritas motor agar dapat bergerak maju, mundur, kekanan, dan kekiri diperlukan transistor yang dapat tahan terhadap tegangan $24 \mathrm{~V}$, maka dipilih transistor BD139 yang terhubung dengan kumparan relay.

\section{HASIL DAN PEMBAHASAN}

Robot pemindah bunga yang dihasilkan pada penelitian ini ditunjukkan pada gambar 4.1 .

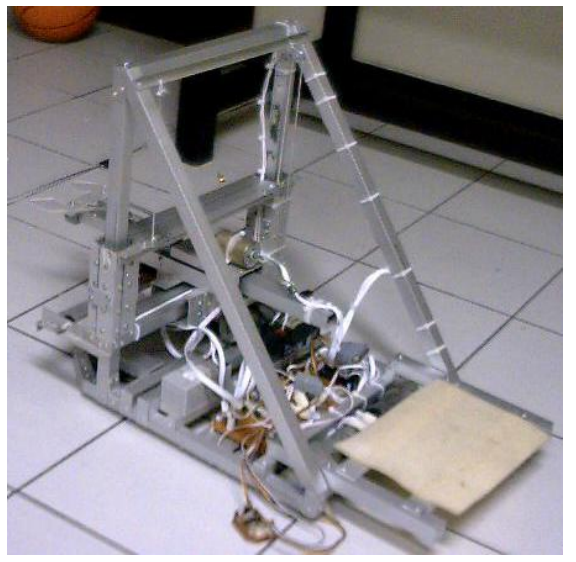

Gambar 4.1 Robot Pemindah Bunga

Untuk mengetahui apakah sistem sudah berfungsi dengan baik, maka pada penelitian ini dilakukan beberapa pengujian, diantaranya adalah pengujian proses mengambil bunga, proses meletakkan bunga, dan pengujian tingkat keberhasilan robot dalam menjalankan fungsinya.

\subsection{Pengujian Proses Mengambil Bunga}

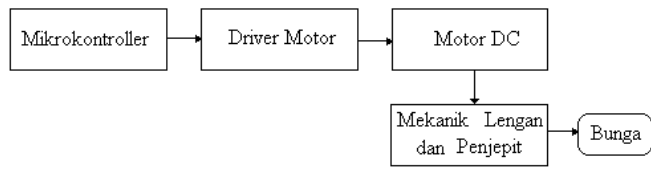

Gambar 4.2 Diagram Blok Pengujian Proses Mengambil Bunga
Tabel 4.1 Pengujian Proses Mengambil Bunga

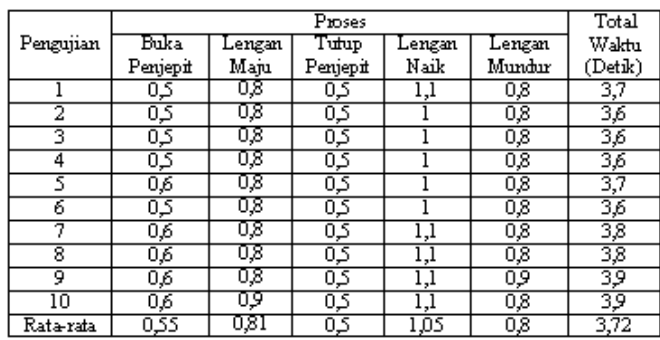

Sesuai dengan hasil pengujian yang ada pada tabel 4.1, rata-rata waktu yang dibutuhkan untuk proses membuka penjepit adalah 0,55 , lengan maju $=0,8$, tutup penjepit $=0,5$, lengan naik $=1,05$, lengan mundur $=0,8$. Sedangkan waktu rata-rata yang dibutuhkan untuk proses mengambil bunga yang merupakan gabungan dari kelima sub proses tersebut adalah 3,72 detik. Proses mengambil bunga yang dilakukan oleh robot ditunjukkan pada gambar 4.3.

Perbedaan total waktu pada setiap pengujian sangat sedikit, sehingga dapat disimpulkan bahwa sistem pengambilan bunga dapat berjalan sesuai dengan yang diharapkan.

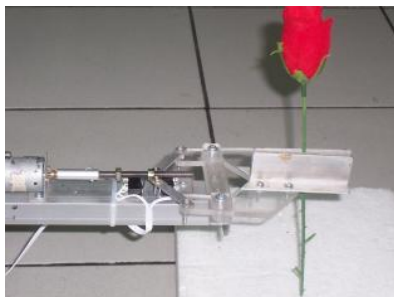

Gambar 4.3 Robot Mengambil Bunga

\subsection{Pengujian Proses Meletakkan Bunga}

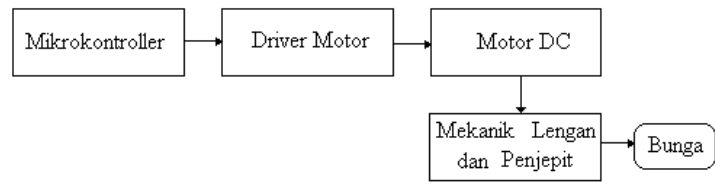

Gambar 4.4 Diagram Blok Pengujian Proses Meletakkan Bunga 
Tabel 4.2 Hasil Pengujian Proses Meletakkan Bunga

\begin{tabular}{|c|c|c|c|c|c|}
\hline \multirow[b]{2}{*}{ Pengujian } & \multicolumn{4}{|c|}{ Proses } & \multirow{2}{*}{$\begin{array}{c}\text { Total } \\
\text { Waktu } \\
\text { (Detik) }\end{array}$} \\
\hline & $\begin{array}{l}\text { Lengan } \\
\text { Maju }\end{array}$ & $\begin{array}{l}\text { Lengan } \\
\text { Turun }\end{array}$ & $\begin{array}{c}\text { Buka } \\
\text { Penjepit }\end{array}$ & $\begin{array}{l}\text { Lengan } \\
\text { Mundur }\end{array}$ & \\
\hline 1 & 0,8 & 0,9 & 0,5 & 0,8 & 3 \\
\hline 2 & 0,8 & 0,8 & 0,5 & 0,8 & 2,9 \\
\hline 3 & 0,8 & 0,8 & 0,5 & 0,8 & 2,9 \\
\hline 4 & 0,8 & 0,9 & 0,5 & 0,8 & 3 \\
\hline 5 & 0,9 & 0,9 & 0,5 & 0,8 & 3,1 \\
\hline 6 & 0,8 & 0,8 & 0,5 & 0,8 & 2,9 \\
\hline 7 & 0,9 & 0,9 & 0,5 & 0,8 & 3,1 \\
\hline 8 & 0,9 & 0,9 & 0,5 & 0,9 & 3,2 \\
\hline 9 & 0,9 & 0,8 & 0,5 & 0,8 & 3 \\
\hline 10 & 0,9 & 0,8 & 0,5 & 0,9 & 3,1 \\
\hline Rata-rata & 0,85 & 0,85 & 0,5 & 8,2 & 3,02 \\
\hline
\end{tabular}

\section{Hasil dan Analisa:}

Sesuai dengan hasil pengujian yang ditunjukkan pada tabel 4.2, rata-rata waktu yang dibutuhkan untuk proses lengan maju adalah 0,85 , lengan turun $=$ 0,85 , penjepit $=0,5$, dan lengan mundur $=8,2$. Sedangkan waktu rata-rata yang dibutuhkan untuk proses meletakkan bunga yang merupakan gabungan dari keempat sub proses tersebut adalah 3,02 detik. Dari hasil pengujian tersebut juga dapat diketahui bahwa perbedaan waktu pada setiap pengujian sangat sedikit, sehingga dapat disimpulkan bahwa sistem pengambilan bunga dapat berjalan sesuai dengan yang diharapkan.

\subsection{Pengujian Sistem Keseluruhan}

Pengujian sistem keseluruhan merupakan pengujian dengan menggabungakan seluruh sistem, baik hardware, mekanik maupun program di PC dan dilakukan beberapa kali dengan cahaya yang normal tidak terlalu terang dan tidak terlalu gelap. Hal ini dilakukan agar ketika dilakukan pengujian posisi dan jarak pada cahaya biasa memiliki tingkat keberhasilan yang lebih tinggi.

\subsubsection{Pengujian Waktu Proses Robot}

Pengujian waktu proses robot dilakukan untuk mendapatkan data mengenai berapa lama waktu yang dibutuhkan robot untuk melakukan fungsinya dalam beberapa kali percobaan. Urutan gerak robot pada pengujian waktu proses robot ditunjukkan pada gambar 4.5.

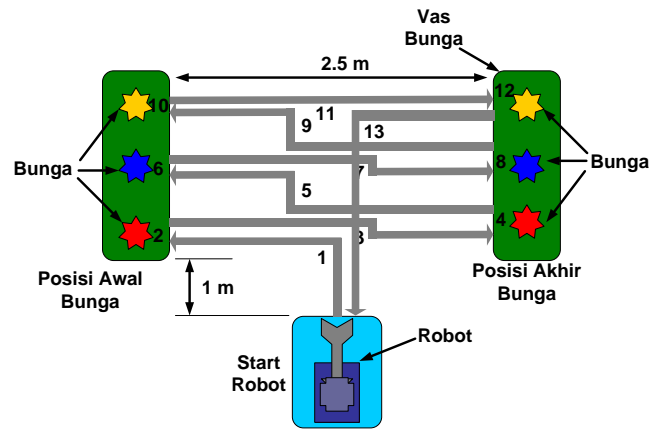

Gambar 5.5 Urutan Gerak Robot

Tabel 5.3 Data Pengujian Waktu Proses

\begin{tabular}{|c|c|c|c|}
\hline Pengujian & Proses & Waktu & $\begin{array}{c}\text { Total } \\
\text { Waktu }\end{array}$ \\
\hline \multirow{3}{*}{1} & $\begin{array}{l}\text { Mengambil bunga warna merah } \\
\text { hingga meletakkannya ke vas }\end{array}$ & 02.03 & \multirow{3}{*}{05.32} \\
\hline & $\begin{array}{l}\text { Mengambil bunga wama biru } \\
\text { hingga meletakkannya ke vas }\end{array}$ & 01.37 & \\
\hline & $\begin{array}{l}\text { Mengambil bunga wanna kuning } \\
\text { hingga meletakkannya ke vas }\end{array}$ & 01.52 & \\
\hline \multirow{3}{*}{2} & $\begin{array}{l}\text { Mengambil bunga warna merah } \\
\text { hingga meletakkannya ke vas }\end{array}$ & 01.54 & \multirow{3}{*}{05.19} \\
\hline & $\begin{array}{l}\text { Mengambil bunga warna biru } \\
\text { hingga meletakkannya ke vas }\end{array}$ & 01.31 & \\
\hline & $\begin{array}{l}\text { Mengambil bunga warna kuning } \\
\text { hingga me letakkannya ke vas }\end{array}$ & 02.04 & \\
\hline \multirow{3}{*}{3} & $\begin{array}{l}\text { Mengambil bunga wama merah } \\
\text { hingga meletakkannya ke vas }\end{array}$ & 02.10 & \multirow{3}{*}{05.47} \\
\hline & $\begin{array}{l}\text { Mengambil bunga warna biru } \\
\text { hingga meletakkannya ke vas }\end{array}$ & 01.40 & \\
\hline & $\begin{array}{l}\text { Mengambil bunga wama kuning } \\
\text { hingga meletakkannya ke vas }\end{array}$ & 01.57 & \\
\hline \multirow{3}{*}{4} & $\begin{array}{l}\text { Mengambil bunga wama merah } \\
\text { hingga meletakkannya ke vas }\end{array}$ & 02.12 & \multirow{3}{*}{05.46} \\
\hline & $\begin{array}{l}\text { Mengambil bunga wama biru } \\
\text { hingga meletakkannya ke vas }\end{array}$ & 01.47 & \\
\hline & $\begin{array}{l}\text { Mengambil bunga wama kuning } \\
\text { hingga meletakkannya ke vas }\end{array}$ & 01.51 & \\
\hline \multirow{3}{*}{5} & $\begin{array}{l}\text { Mengambil bunga warna merah } \\
\text { hingga meletakkannya ke vas }\end{array}$ & 02.15 & \multirow{3}{*}{05.51} \\
\hline & $\begin{array}{l}\text { Mengambil bunga warna biru } \\
\text { hingga meletakkannya ke vas }\end{array}$ & 01.50 & \\
\hline & $\begin{array}{l}\text { Mengambil bunga warna kuning } \\
\text { hingga meletakkannya ke vas }\end{array}$ & 01.46 & \\
\hline
\end{tabular}

Dari tabel 5.3 didapatkan data waktu proses robot dalam melaksanakan fungsinya, yaitu mengambil dan meletakkan bunga pada vas. Perbedaan waktu proses pengambilan bunga dan peletakan bunga ke vas bunga pada setiap percobaan disebabkan oleh beberapa faktor antara lain cahaya pada lingkungan pengujian, penggunaan roda bebas pada sisi depan robot dan penempatan dan model peletakan bunga warna merah, biru, dan kuning yang berbeda.

\subsubsection{Pengujian Tingkat Keberhasilan Robot}

Pada pengujian sistem secara keseluruhan ini, diketahui kemampuan 
robot dalam menjalankan tugas yaitu mengambil bunga dan memindahkan bunga kedalam vas bunga dengan tatanan tertentu. Dimana pengambilan data dilakukan dengan jarak antara bunga dengan vas adalah $\pm 2,5$ meter. Hasil pengujian ditunjukkan pada tabel 4.4.

Tabel 5.4 Data Pengujian Sistem Keseluruhan

\begin{tabular}{|c|c|c|c|c|c|c|}
\hline Target & $\begin{array}{l}\text { Bunga } \\
\text { Merah }\end{array}$ & $\begin{array}{l}\text { Vas } \\
\text { Pertama }\end{array}$ & $\begin{array}{c}\text { Bunga } \\
\text { Biru }\end{array}$ & $\begin{array}{l}\text { Vas } \\
\text { Kedua }\end{array}$ & $\begin{array}{l}\text { Bunga } \\
\text { Kuning }\end{array}$ & $\begin{array}{l}\text { Vas } \\
\text { Ketiga }\end{array}$ \\
\hline 1 & y & 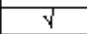 & y & y & y & y \\
\hline 2 & $\mathrm{X}$ & v & $\mathrm{X}$ & V & y & $\mathrm{X}$ \\
\hline 3 & $y$ & $\mathrm{X}$ & v & $\mathrm{X}$ & y & $y$ \\
\hline 4 & $\mathrm{X}$ & $\mathrm{X}$ & v & vi & v & v \\
\hline 5 & v & v & $\mathrm{X}$ & $\mathrm{X}$ & v & 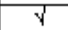 \\
\hline 6 & v & y & v & y & y & y \\
\hline 7 & 1 & 1 & $\checkmark$ & 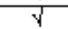 & $\mathrm{X}$ & $\mathrm{X}$ \\
\hline 8 & 9 & 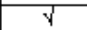 & v & $\mathrm{X}$ & v & v \\
\hline 9 & v & y & v & v & v & y \\
\hline 10 & v & $\mathrm{X}$ & $\mathrm{X}$ & v & v & $\mathrm{X}$ \\
\hline Error & $20 \%$ & $30 \%$ & $30 \%$ & $30 \%$ & $20 \%$ & $30 \%$ \\
\hline $\begin{array}{l}\text { Rata-rata } \\
\text { Eror }\end{array}$ & \multicolumn{6}{|c|}{ Rata-rata Eror Sistem $=26.67 \%$} \\
\hline $\begin{array}{c}\text { Rata-rata } \\
\text { Keberhasilan }\end{array}$ & \multicolumn{6}{|c|}{ Rata-rata Eror Sistem $=73.33 \%$} \\
\hline
\end{tabular}

Keterangan : $\sqrt{ }$ (tepat sasaran)

$\mathrm{X}$ (tidak tepat sasaran)

Dari tabel 5.4, ternyata masih terdapat beberapa kegagalan robot dalam menjalankan tugasnya. Intensitas cahaya ruang yang berubah-ubah saat pengujian, bentuk mekanik penjepit dan kecepatan respon kamera dalam mengambil gambar mempengaruhi hasil percobaan. Sehingga terjadi kondisi dimana robot agak terlambat dalam merespon perubahan target, baik posisi maupun luas. Pengujian sistem secara keseluruhan dilakukan sebanyak 10 kali, dan hasilnya adalah robot memiliki rata-rata eror sebesar $26.67 \%$ atau tingkat rata-rata keberhasilan sebesar $73.33 \%$

\section{KESIMPULAN DAN SARAN 6.1 Kesimpulan}

1. Total waktu yang dibutuhkan untuk proses mengambil dan meletakkan bunga antara percobaan satu dengan yang lain mempunyai perbedaan yang relatif kecil yaitu antara 0,1 hingga 0,3 detik.

2. Waktu rata-rata yang dibutuhkan robot pada proses mengambil bunga adalah
3,72 menit, sedangkan untuk proses meletakkan bunga membutuhkan ratarata waktu 3,02 detik.

3. Dalam 10 kali pengujian sistem robot secara keseluruhan, tingkat keberhasilan rata-rata robot adalah $73,33 \%$

4. Cahaya pada lingkungan robot, kecepatan respon kamera dalam mengambil gambar, dan bentuk mekanik penjepit dapat mempengaruhi tingkat keberhasilan robot dalam menjalankan fungsinya.

\subsection{Saran}

Berikut ini adalah saran-saran yang dapat menjadi pertimbangan untuk pengembangan lebih lanjut :

1. Untuk mendapatkan pergerakan yang lebih natural, system roda dapat diganti dengan system kaki.

2. Setiap motor yang ada pada robot hendaknya menggunakan motor baru dengan spesifikasi yang sama sehingga kesamaan putaran motor lebih terjamin.

\section{DAFTAR PUSTAKA}

Hilmi, Badrul, "Desain dan Simulasi Robot Penunjuk Arah di Lingkungan PENS - ITS", Politeknik Elektronika Negeri Surabaya - ITS, Surabaya, 2005.

Murtiningsih. 2006. Berkreasi dengan Bunga Kering. Jakarta: AgroMedia Pustaka.

Nalwan, Paulus Andi. 2003. Panduan Praktis Teknik Antarmuka dan Penrograman Mikrokontroler AT89C51. Jakarta: PT Elex Media Komputindo.

Petruzella, Frank D. 1996. Elektronik Industri. Yogyakarta: PT Andi Offset.

Pitowarno, Endra. 2006. Robotika : Disain, Kontrol, dan Kecerdasan Buatan. Yogyakarta: PT Andi Offset. 
Retna Prasetia \& Catur Edi Widodo, Interfacing Port Paralel dan Port Serial Komputer degan Visual Basic 6.0.

Rizqi Firmansyah, "Robot Pengelasan", Politeknik Elektronika Negeri Surabaya ITS, Surabaya, 2006.

Saputro, Rejeki Agung, "Robot Sumo", Politeknik Elektronika Negeri Surabaya ITS, Surabaya, 2006.

ATmegal6", www.atmel.com

,"Photodiode Characteristics and Applications", www.udt.com, 